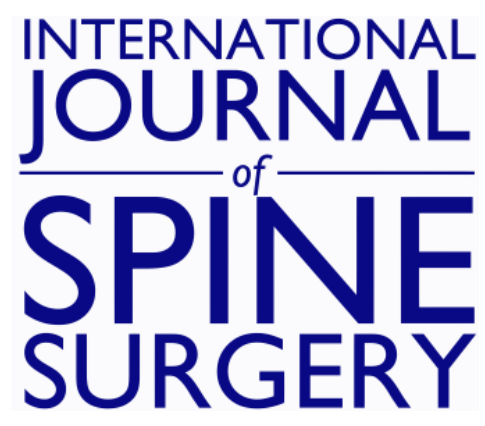

\title{
Minimally Invasive Posterior Tubular Microsurgical Approach for the Management of Symptomatic Synovial Cysts of the Lumbar and Cervical Spine
}

José Antonio Soriano Sánchez, Kai Uwe Lewandrowski, José Alfonso Franco Jímenez, Manuel Eduardo Soto Garcia, Sergio Soriano Solís, Manuel Rodríguez García, Oscar Sanchéz Escandón, Romero Rangel and José Alberto Israel

Int J Spine Surg published online 22 September 2021

http://ijssurgery.com/content/early/2021/09/20/8134

This information is current as of April 26, 2023.

Email Alerts Receive free email-alerts when new articles cite this article. Sign up at: http://ijssurgery.com/alerts 


\title{
Minimally Invasive Posterior Tubular Microsurgical Approach for the Management of Symptomatic Synovial Cysts of the Lumbar and Cervical Spine
}

\author{
JOSÉ ANTONIO SORIANO SÁNCHEZ, ${ }^{1}$ KAI UWE LEWANDROWSKI, MD, ${ }^{2-4}$ JOSÉ ALFONSO FRANCO \\ JÍMENEZ, MD ${ }^{1,5}$ MANUEL EDUARDO SOTO GARCIA, MD ${ }^{1}{ }^{1}$ SERGIO SORIANO SOLÍS, MD ${ }^{1}$ \\ MANUEL RODRÍGUEZ GARCÍA, MD ${ }^{1}$ OSCAR SANCHÉZ ESCANDÓN, MD,${ }^{1}$ ROMERO RANGEL, \\ JOSÉ ALBERTO ISRAEL, MD, MSC ${ }^{1,6,7}$ \\ ${ }^{I}$ Spine Clinic, The American-British Cowdray Medical Center I.A.P., Campus Santa Fe, Mexico City, Mexico, ${ }^{2}$ Center for Advanced Spine Care of Southern \\ Arizona and Surgical Institute of Tucson, Tucson, Arizona, ${ }^{3}$ Department of Orthopaedics, Fundación Universitaria Sanitas, Bogotá, Colombia, ${ }^{4}$ Department of \\ Orthopaedics at UNIRIO, Federal University of the State of Rio de Janeiro, Rio de Janeiro, Brazil, ${ }^{5}$ Pediatric Neurosurgery, Children's Hospital, Federico Gómez, \\ Mexico City, Mexico, ${ }^{6}$ Regional General Hospital \#25 of the National Institute of Social Security, Mexico City, Mexico, ${ }^{7}$ University of Sonora, Sonora, Mexico
}

\begin{abstract}
Background: Synovial cysts are commonly associated with instability. Whether to fuse patients is a matter of controversy. Simple resection may offer favorable clinical outcomes but may come at the expense of recurrence rate. We describe our experience with the minimally invasive management of these lesions using microsurgical dissection through a tubular retractor system.

Materials: A retrospective cohort study of symptomatic patients with synovial cysts treated by a minimally invasive tubular approach from 2001 to 2018 was performed. We evaluated variables such as preexisting spinal pathology, previous surgery, radiological findings, comorbidities, and secondary surgery requiring fusion. We used the visual analog scale (VAS), the Oswestry disability index (ODI), and the Macnab scale for clinical evaluation.

Results: There were 35 patients with a mean age of 63 years. The mean duration of symptoms before surgery was 195 weeks. Axial pain was present in $77.1 \%$ of cases; radiculopathy was the main symptom in $94.3 \%$ of cases. The most frequent site was L4-L5 (62.8\%). Presenting comorbidities were lumbar stenosis (28.6\% of patients), spondylolisthesis $(8.6 \%)$, and facet hypertrophy (31.4\%). Mean surgical time was 143 minutes (range, 55-360 minutes). The mean hospital stay was 2 days, ranging from 1 to 5 days. No complications were encountered as a consequence of the surgical procedure. All patients showed neurophysiological improvement after surgical intervention. A total of 34 patients $(97.14 \%)$ showed clinical improvement at the end of follow-up, averaging 17 months and ranging from 1 to 60 months, 28 patients $(80 \%)$ had good to excellent Macnab outcomes, 6 patients $(17.14 \%)$ were rated as fair, and $1(2.86 \%)$ patient had a poor Macnab outcome. Radicular VAS significantly changed $(P<.05)$ from a preoperative mean of $8.23 \pm 1.24$ to a postoperative mean of $2.23 \pm 1.94$. ODI significantly decreased $(P<.05)$ from a preoperative of mean of $41.02 \pm$ 12.56 to a postoperative of mean of $11.82 \pm 10.56$. We performed fusion at initial surgery in $37.1 \%$ of cases; however, 3 more patients required secondary fusion at follow-up.

Conclusion: Our series corroborates the prior literature with a low incidence of synovial cysts in the cervical spine and none in the thoracic spine. The present work shows the efficacy of minimally invasive surgery in the treatment of these lesions. Synovial cysts were associated with instability, ultimately requiring fusion in the majority of patients. The authors' study includes a large patient series with minimally invasive microsurgical decompression performed through a tubular retractor to date.
\end{abstract}

Level of Evidence: 3.

Minimally Invasive Surgery

Keywords: minimal invasive spine surgery, synovial cyst, instability, lumbar and cervical spine, tubular approach, fusion, posterior approach

\section{INTRODUCTION}

Synovial cysts cause radiculopathy of the exiting nerve root by compressive foraminal stenosis, rarely causing axial pain at initial presentation. ${ }^{1-3}$ Their most frequent localization is at the facet joints of
L4-L5 $5^{1,2,4-7}$ and are rarely encountered at the cervical or thoracic spine. ${ }^{1,2}$ Synovial cysts are frequently associated with vertebral instability and other degenerative spinal diseases. ${ }^{1,3,6,8,9}$ Surgical management is considered the treatment of choice $^{5,9-12}$ due to a lower recurrence rate and more 
significant improvement of neurological symptoms than conservative or interventional treatments, such as surgical drainage or intralesional steroid injection. ${ }^{5,9,11,13}$ Current research focuses on the use of minimally invasive surgery as an alternative to conventional open surgery, with lower risks and similar outcomes. ${ }^{13-16}$ Some authors perform contralateral approaches, advocating better exposure and lower postoperative instability risk due to limited articular bone resection and direct view of the lesion. ${ }^{15-18}$ Whether to perform a facet joint resection during a spinal fusion or a simple decompression is controversial. ${ }^{11,14,19,20}$ However, evidence suggests that fused patients have lower recurrences ${ }^{4,6,7,10,12,16,19-25}$ and, in some cases, better clinical results with decreased postoperative pain. ${ }^{5,25}$ Consequently, the debate on the optimal treatment strategy for patients with symptomatic synovial cysts continues. We present our 10-year experience in minimally invasive management of these lesions by a tubular approach.

\section{MATERIAL AND METHODS}

\section{Study Design and Patients}

We performed a retrospective cohort study of 35 patients with symptomatic synovial cysts of the lumbar and cervical spine treated by a single surgeon with a minimally invasive tubular microsurgical approach between December 2001 and May 2018.

\section{Inclusion and Exclusion Criteria}

Only patients who underwent spinal surgery because of symptomatic synovial facet cysts and other associated degenerative spine conditions responsive to decompression and confirmed by magnetic resonance imaging or computed tomography were selected for this study. Therefore, the presence of spondylolisthesis or stenosis in the central or lateral spinal canal was not a contraindication to including patients in this analysis. Patients with unmanageable radicular pain unresponsive to a minimum of 12 weeks of medical and interventional conservative care with a positive Lasègue's tension sign and minimal low back pain were included. However, patients with other concomitant conditions that could impair the authors' ability to determine clinical improvements with surgical treatment of synovial cysts were excluded. For example, a concurrent diagnosis of infection, tumor or metastatic disease, recent spinal fracture, coronal or sagittal plane deformity above $30^{\circ}$, behavioral abnormalities, dependence on pain killers, or any electrodiagnostic evidence of chronic demyelination or denervation in the dermatomes innervated by the affected surgical nerve roots prompted exclusion from the study.

\section{Preoperative Work-Up and Clinical Decision- Making}

All of our patients were evaluated preoperatively with a thorough physical examination, standing and dynamic x-rays of the region of interest, and magnetic resonance imaging or computed tomography. Additionally, neurophysiologic studies were performed to support clinical decision-making in patients with equivocal findings. Diagnostic facet and selective nerve root blocks were also used. Bone densitometry was performed for patients over 50 years old who were scheduled for fusion. The surgical technique choice was made according to the patient's clinical presentation, synovial cyst location, and the presence of instability. A simple resection of the lumbar cyst was performed in patients without associated instability or other painful spinal pathologies. Minimally invasive transforaminal lumbar interbody fusion (MI-TLIF) was the procedure of choice in patients with spondylolisthesis or instability of the facet joint, as demonstrated by diastasis of the joint space and thickening of the ligamentum flavum. ${ }^{4,10,11,14,16,21,26}$ For cervical spine cysts, a simple resection was performed in the absence of instability. In patients with cervical radiculopathy in addition to neck pain, we performed a foraminotomy as needed. Patients with concomitant instability at the surgical level should be treated with a simultaneous fusion procedure. ${ }^{19,27,28}$ The authors' decision-making algorithm is summarized in Figure 1.

\section{Positioning, Anesthesia, and Surgical Approach}

Patients were placed in a prone position, and surgery was performed under total intravenous anesthesia without neuromuscular blockade to permit intraoperative multimodal neurophysiologic monitoring in all patients. ${ }^{29-33}$ After fluoroscopic identification of the surgical level, a paramedian incision was made approximately $5 \mathrm{~mm}$ from the midline. A muscle-splitting dissection technique was used to facilitate tubular retractor placement in the posterior lumbar spine. Serial dilation was used. 


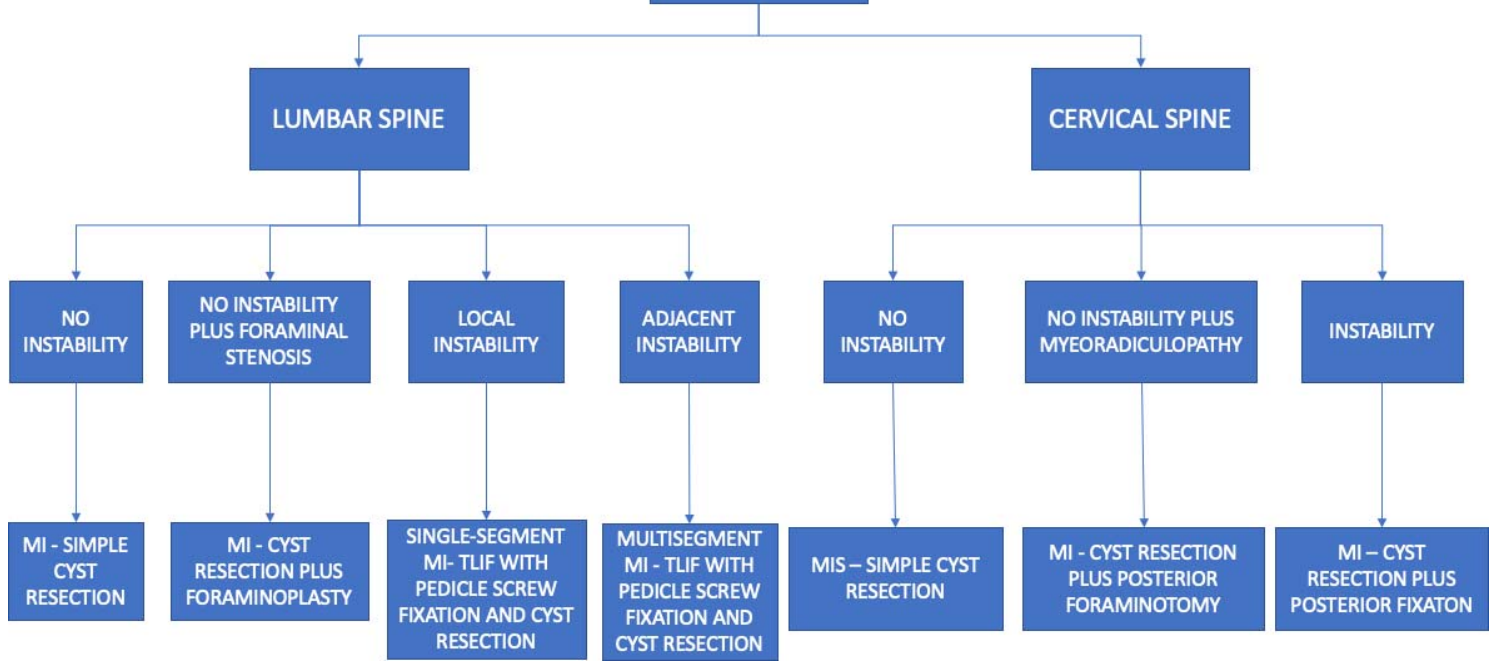

Figure 1. Decision-making algorithm.

Throughout the operation, bipolar electrocautery was used to shrink the synovial tissue and control bleeding, after which a multilayer wound closure was performed. The patient was placed in a prone position with a Mayfield head holder, with the head in capital flexion and the cervical spine in extension (military position) for the cervical procedures.

\section{Surgical Techniques}

\section{Simple Lumbar Synovial Cyst Resection}

Patients without lumbar instability and no other symptomatic compressive pathology underwent simple resection of the synovial cyst via an interlaminar approach. Typically, a 14-mm tube was sufficient to permit the surgeon to perform the operation. Depending on the cyst's relation to the lamina, we chose the rostral or the caudal lamina to gain access to the cyst with a high-speed drill. Most synovial cysts required minimal laminar resection. At times, partial resection of the pars interarticularis was needed to remove huge synovial cysts. In these cases, the authors often first aspirated the cyst before commencing the decompression with drills and rongeurs. The authors emphasized limiting the medial facet resection to less than $50 \%$ to avoid iatrogenic instability. Typically, the decompression was begun medially with partial resection of the ligamentum flavum to accomplish a clear view of the dural sac. Rarely, adhesions of the synovial cyst tissue to the dura could not be safely dissected. To avoid cerebrospinal fistula leakage, a sharp dissection of adherent cyst tissues was occasionally required, leaving some synovial membrane on the dura. Figures 2 and 3 demonstrate the surgical technique.

\section{Lumbar Foraminoplasty}

For selected cases with radiculopathy in addition to low back pain and foraminal stenosis at the level of the synovial cyst and no local instability, a foraminoplasty was additionally performed to allow for simple resection in the same segment. Once the synovial cyst had been removed, we proceeded to perform an undercutting of the adjacent facet joint junction using an ultrasonic bone aspiration device with careful attention to resect no more than $50 \%$ of the facet joint. Thorough surgical decompression of

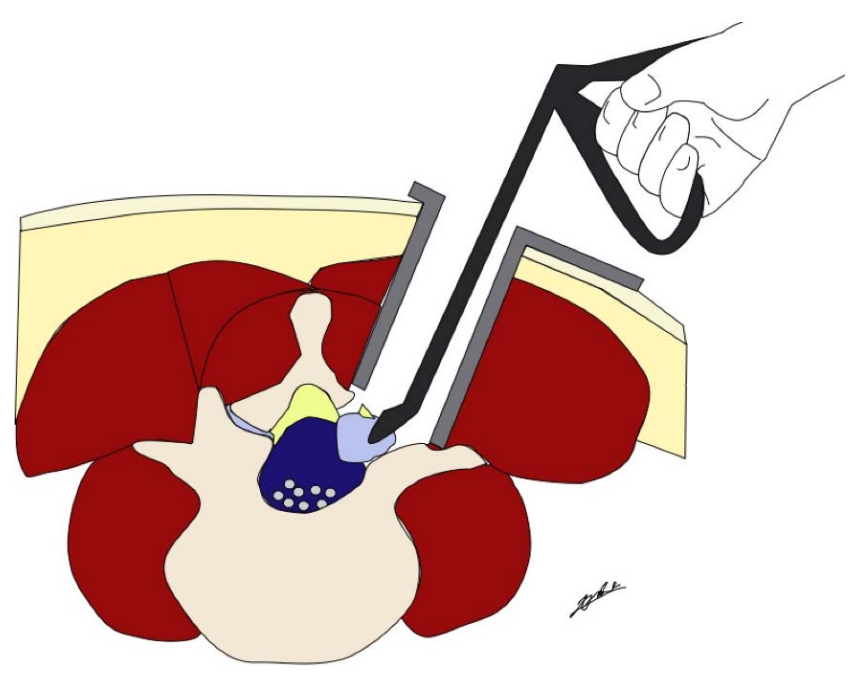

Figure 2. Schematic drawing of simple lumbar synovial cyst resection. 


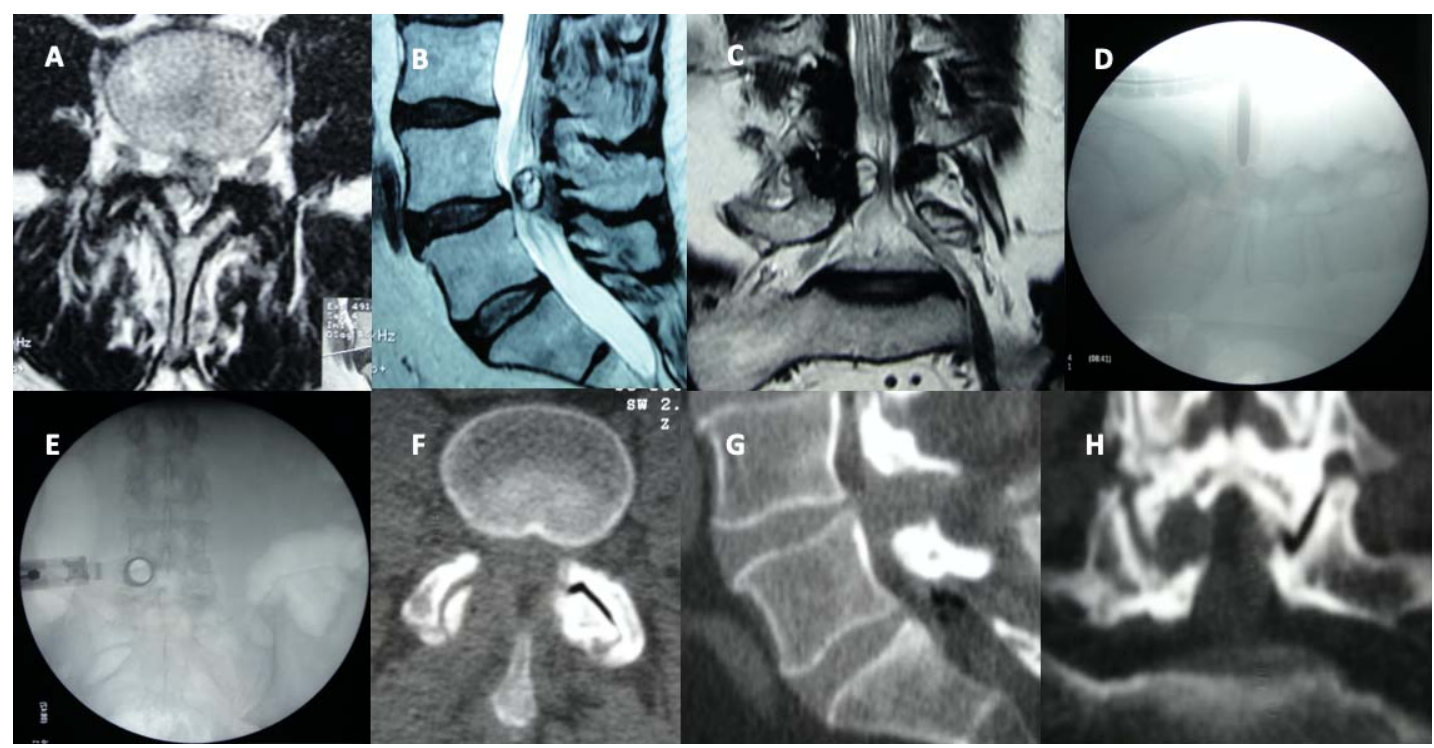

Figure 3. An illustrative case demonstrating an L4-L5 right synovial cyst resection (A). Axial (B), sagittal (C), and coronal T2-weighted magnetic resonance imaging images show a synovial cyst causing lumbar spinal stenosis. Intraoperative lateral (D) and anterior-posterior fluoroscopic views show the tubular retractor positioned right above the facet-laminar junction. Postoperative axial $(F)$, sagittal $(G)$, and coronal $(\mathrm{H})$ computed tomography scans demonstrate laminotomy and validate the cyst resection.

the foramen with resection of the tip of the inferior articular process is of the utmost importance in these cases as the resolution of clinical symptoms may be otherwise incomplete.

\section{MI-TLIF}

Patients with Meyerding grade I or higher underwent MI-TLIF using a senior author's modified technique described herein. The skin incision was placed $2 \mathrm{~cm}$ lateral to the lateral interpedicular line, as verified on the intraoperative fluoroscopic posterior-anterior view. The surgical level was confirmed in the lateral projection. A surgical access corridor was created, exploiting the intermuscular plane between the longissimus and iliocostalis, easily identified by digital palpation. A $20-\mathrm{mm}$ tubular retractor was placed on top of the facet joint complex to best facilitate the insertion of an interbody cage. The decompression was begun from lateral to medial using a high-speed drill. The authors' preference was to leave a thin portion of the most medial part of the superior articular process and the inferior articular process intact to avoid dural tears. Once the intervertebral disc was exposed, a bayonetted knife was used for the annulotomy, and a port cannula was positioned in the intervertebral space through the tubular access retractor to facilitate the discectomy and endplate preparation done with the use of disc rongeurs and endplate dissectors. Bone graft was harvested locally, mixed with a demineralized bone matrix, and abundantly placed into the disc space through the cannula and within the polyetheretherketone interbody fusion cage. The latter was inserted over a Kirschner wire. The authors aimed to position a single interbody fusion cage into the anterior third in the lateral projection and across the midline in the posterior-anterior projection. After completing the interbody fusion with cage insertion, we completed the decompression by removing the remaining medial portion of the inferior articular process and superior articular process, ligamentum flavum, and the cyst. The MI-TLIF was then concluded with the placement of percutaneous pedicle screws. Briefly, a Jamshidi needle was used to cannulate the surgical pedicles under posterior-anterior and lateral fluoroscopic control, and the cannulated screws were inserted via a Kirschner wire. The screws-rod construct was completed by securing a rod with set screws under slight compression that was intentionally chosen $5 \mathrm{~mm}$ longer than the distance measured between the screws. Figures 4 and 5 demonstrate the surgical technique.

\section{Simple Cervical Synovial Cyst Resection}

This procedure was done in patients without instability or associated cervical compressive pathologies. The skin incision was marked over the surgical level by the aid of fluoroscopy. On the true anterior-posterior projection, the skin was marked 2 $\mathrm{cm}$ lateral from the midline. The lateral view was used to confirm the procedure's cervical level 

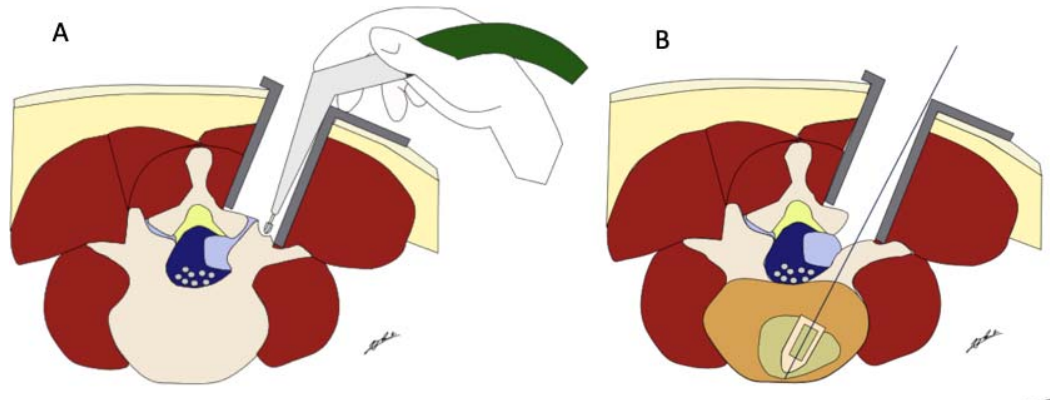

Figure 4Schematic synovial cyst resection and transforaminal lumbar interbody fusion. (A) Lateral facetectomy by high-speed drill. (B) Bullet cage inserted by aid of Kirschner wire once the synovial cyst has been completely removed and the thecal sac decompressed. (C) Medial ligamentum flavum incision for medial to lateral dissection from underlying normal dura to synovial cyst capsule. (D) Synovial cyst resection with overlying ligamentum flavum.
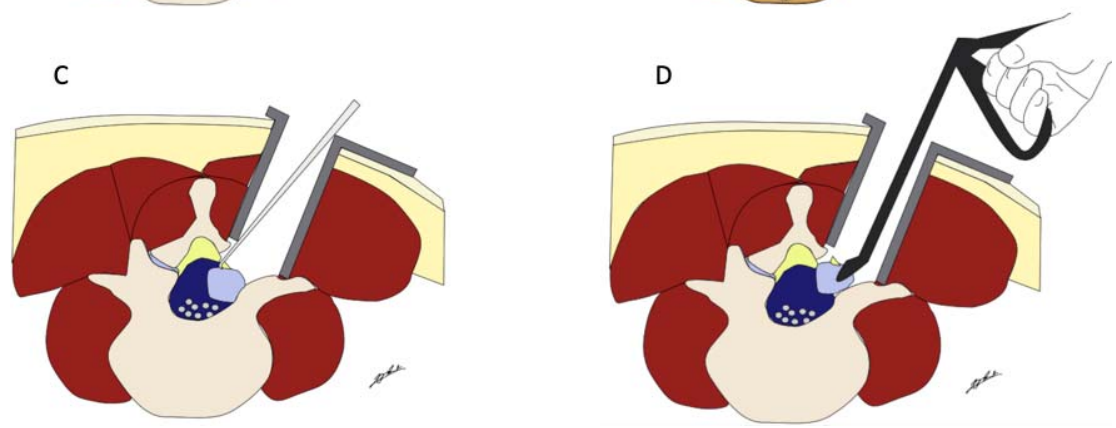

requiring decompression properly. We performed a muscle-splitting dissection technique through the muscle bundles in each layer in the direction of its fibers until the laminofacet junction was reached. Then, we inserted the cylindrical dilators above the facet junction using fluoroscopy to place a tubular retractor. Often, a 14-mm tube was sufficient to resect synovial cysts. Depending on the relation of the cyst to the laminae, we chose the upper or the lower lamina for high-speed drilling. The decompression commenced from the most medial aspect of the ligamentum flavum and proceeded laterally, dissecting the plane between the dural sac and the cyst's sac. Complete cyst resection and extirpation may be facilitated by a combination of bipolar electrocautery and mechanical traction with rongeurs and disc clamps. Careful hemostasis was confirmed before closing the soft tissues by a

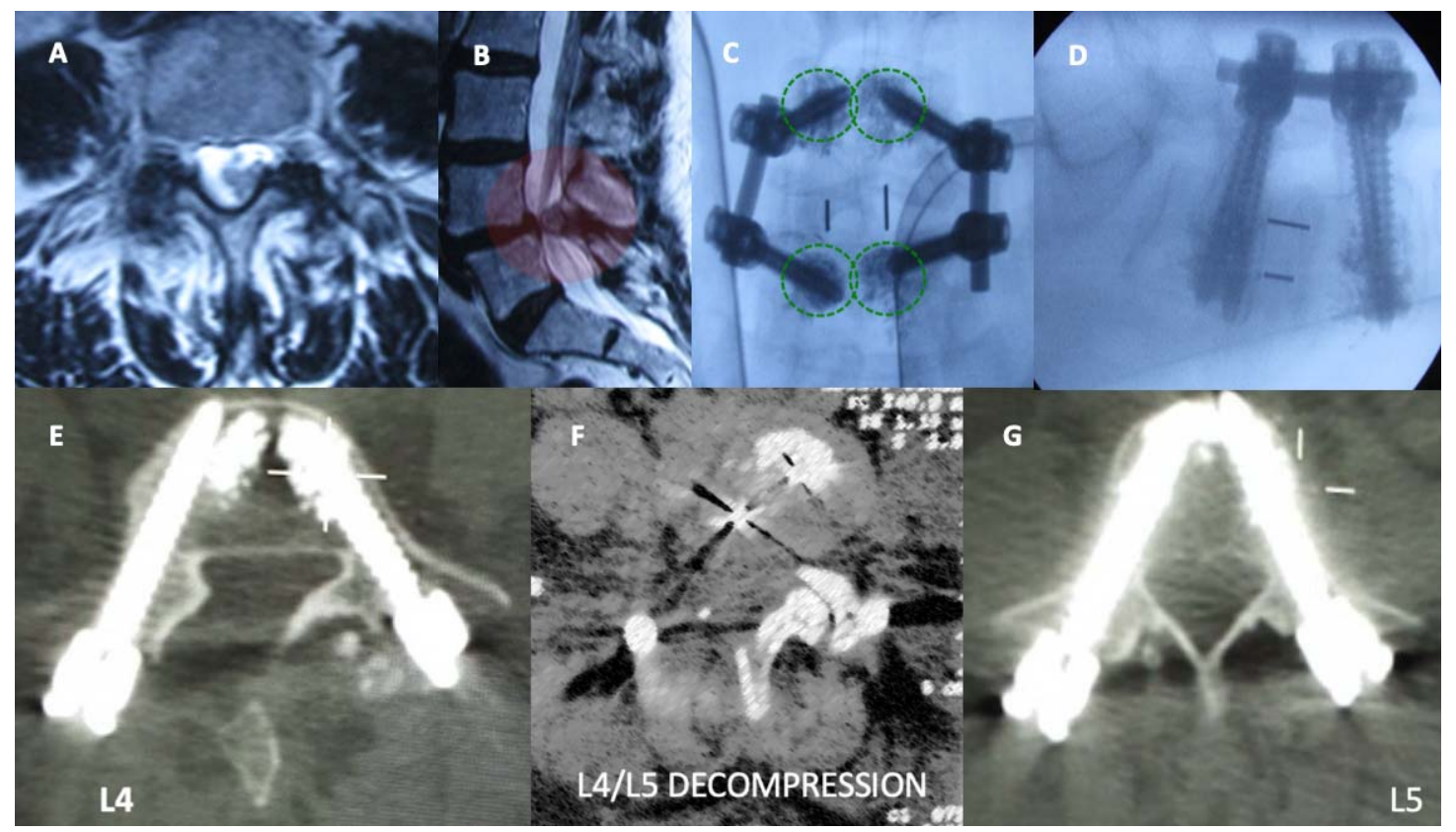

Figure 5. An illustrative transforaminal lumbar interbody fusion (TLIF) case shows axial (A) and sagittal (B) magnetic resonance imaging scans demonstrating a huge right synovial cyst at the L4-L5 level. Anterior-posterior (C) and lateral (D) intraoperative fluoroscopic views illustrating TLIF and transpedicular screw fixation augmented with bone cement because of osteopenia evident on the preoperative bone density scan. The postoperative axial computed tomography scan images (E$\mathrm{G})$ validate the L4-level cyst resection, adequate position of the interbody fusion cage, and the L4 and L5 pedicle screws without breaches. 

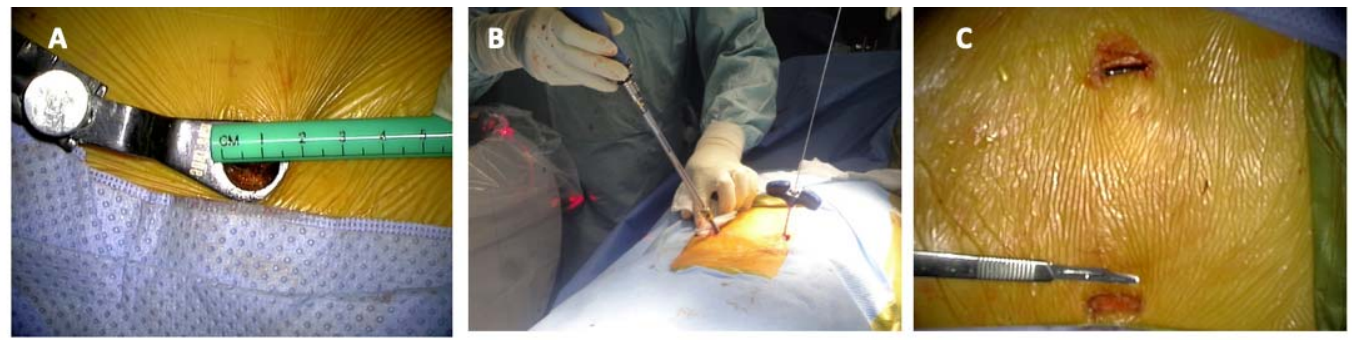

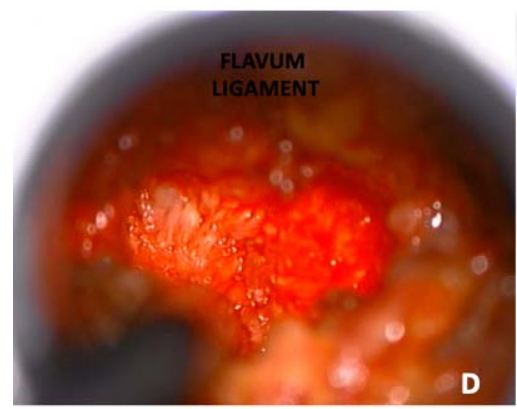

LATERAL

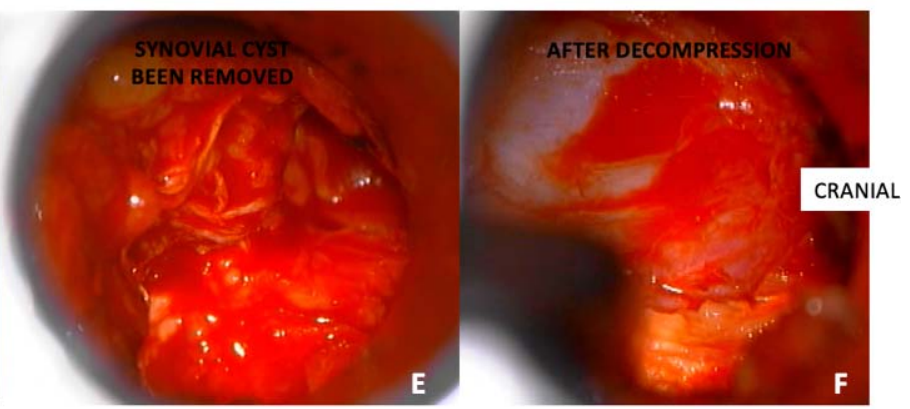

LATERAL

LATERAL

Figure 6. Continuation of the same illustrative case shown in Figure 5. A 14-mm tube was placed for right-sided transforaminal lumbar interbody fusion and synovial cyst resection (A). Bilateral transpedicular screw fixation after transforaminal interbody fusion and cyst resection was performed (B). Bilateral skin incisions (right side at the bottom, left side at the top) were made (C). The ligamentum flavum was identified (D), and the synovial cyst (at the top) was noted to be adherent to it (E). The decompressed dural sac was visualized after completion of the cyst resection.

multilayer technique. Figure 6 demonstrates the surgical procedure.

\section{Cervical Foraminotomy}

In patients where the synovial cysts cause both neck pain and radiculopathy due to associated foraminal stenosis, a posterior foraminotomy was performed in addition to the cyst resection. Once the cyst had been thoroughly dissected, we proceeded to identify the exiting nerve root under the laminofacet junction. A standard keyhole foraminotomy was performed with attention to resecting less than $50 \%$ of the overlying facet joint. The authors also used an ultrasonic bone aspiration device to avoid excessive

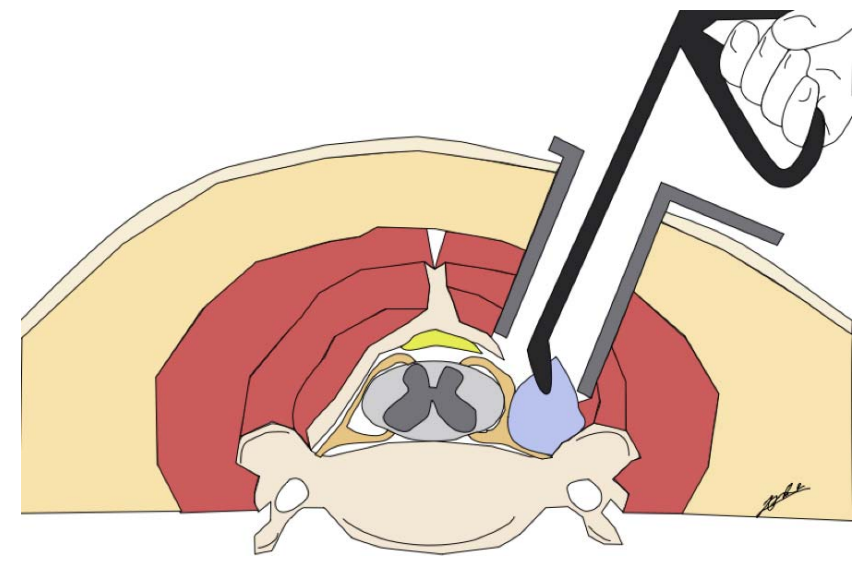

Figure 7. Schematic of simple cervical synovial cyst resection. friction-induced heating of the underlying nerve root and its dorsal root ganglion.

\section{Demographic Data and Outcome Measures}

We collected the following data from the patients' charts: age, sex, body mass index, time to presenting symptoms, preexisting spinal pathology, previous surgery, radiological findings (level, side, and presence of instability by dynamic lumbar plain films), comorbidities, type of surgery, and followup, including patients requiring secondary fusion. Initially, a blinded researcher reviewed the patients' charts retrospectively. The data were entered into a Microsoft Excel spreadsheet. Primary clinical outcome measures were reductions in the visual analog scales $(\mathrm{VAS})^{34}$ for leg, ranging from no pain (0) to worst pain (10), and the Oswestry disability index (ODI). The ODI is a 10-item composite instrument assessing pain intensity, personal care, and function, including walking, lifting, personal care, sitting, standing, sleeping, social interaction, and traveling ${ }^{35,36}$ Postoperatively, patients were scheduled to be seen in follow-up for reevaluation at 6 weeks and then at 3,12, and 24 months. These lumbar primary clinical outcome tools recorded preoperatively and at final follow-up were used for the authors' statistical analysis. This analysis was only performed on patients with lumbar spine synovial cysts 
since there were only 2 patients suffering from synovial cysts of the cervical spine.

\section{Statistical Analysis}

To minimize selection and hindsight bias, this unidentified patient database was transferred to Statistical Package for Social Sciences version 26. Descriptive statistics (mean and standard deviation) and cross-tabulation statistics were computed for two-by-two tables. The Pearson $\chi^{2}$ and the likelihood ratio $\chi^{2}$ tests were used as statistical measures of association between confounding demographic and clinical factors, complications, and clinical outcome measures. The confidence intervals for the likelihood ratios were calculated using the "log method" according to Liberati and Altman et al. ${ }^{37}$

\section{RESULTS}

From December 2001 to May 2018, 35 patients were operated using a minimally invasive tubular approach and included $26(74.3 \%)$ females and 9 $(25.7 \%)$ males, with a mean age of 63 years $(47-80$ range) and a mean time to symptom presentation of 195 weeks, ranging from 4 to 728 weeks.

Thirty-three patients had lumbar cysts, and 2 had facet cysts of the cervical spine. Five patients $(14.3 \%)$ had prior spine surgery, 3 in the lumbar $(8.6 \%)$ spine and $2(5.7 \%)$ in the cervical spine. No previous surgery was performed at the level of the symptomatic synovial cyst; however, a lumbar case was associated with a synovial cyst in the adjacent segment. Radiculopathy was the main symptom in 33 patients (94.3\%), low back or neck pain was the main symptom in a total of 27 patients $(77.1 \%)$, and as few as 10 patients $(28.6 \%)$ had decreased sensitivity and up to 24 patients $(68.6 \%)$ had some degree of paresis. Table 1 summarizes demographic and preoperative data. The most frequently affected segment was L4-L5 in 22 cases $(62.8 \%)$. Left-sided pathology was seen in $17(48.57 \%)$ patients, and the same was observed for right-sided pathology, with just 1 patient having bilateral compromise $(2.86 \%)$. Magnetic resonance imaging findings more frequently encountered were fluid-filled facets instead of facet degeneration in up to $88.57 \%$ of our patients (31 patients). Concurrent spondylolisthesis was found in 17 patients representing 48.6\% (Meyerding grade I), severe facet degeneration (Grogan III and IV) in 11 cases (31.4\%), and 10
Table 1. Demographic and preoperative data.

\begin{tabular}{lr}
\hline & $\boldsymbol{N}(\mathbf{\%})$ \\
\hline Gender & \\
Female & $26(74.28)$ \\
Male & $9(25.71)$ \\
History & \\
Prior surgery & $5(14.28)$ \\
Spinal deformity $<30^{\circ}$ & $4(11.42)$ \\
Symptoms & \\
Radicular pain & $33(94.28)$ \\
Low back pain & $27(77.14)$ \\
Dysesthesia & $10(28.57)$ \\
Weakness & $24(68.57)$ \\
Level & \\
C1-C2 & $1(2.85)$ \\
C3-C4 & $1(2.85)$ \\
L3-L4 & $1(2.85)$ \\
L4-L5 & $22(62.85)$ \\
L5-L6 & $1(2.85)$ \\
L5-S1 & $9(25.71)$ \\
Comorbidities & \\
Spondylolisthesis & $17(48.57)$ \\
Severe facet degeneration & $11(31.42)$ \\
Lumbar canal and recess stenosis & $10(28.57)$ \\
&
\end{tabular}

patients $(28.6 \%)$ with associated lumbar stenosis (Table 2).

Single-level surgery was performed in $23(65.7 \%)$ cases, while 12 patients $(34.3 \%)$ required multiplelevel surgery. An average of 1.4 surgical procedures per patient were done. Simple resection of the synovial cyst was the surgical procedure in 14 patients $(40.0 \%)$. The two cervical patients underwent simple resection of the cyst in 1 patient and with additional foraminotomy in the other patient. In comparison, a MI-TLIF and transpedicular fixation was required in 13 patients $(37.1 \%)$. In the remaining 8 patients $(22.9 \%)$, a foraminotomy (7 patients) with foraminoplasty (1 patient) was performed to manage their symptoms adequately. Adjacent segment pathology developed (radiological findings) in 8 patients $(22.9 \%)$, and 3 patients $(8.57 \%)$ ultimately required late fusion, contributing to a final fusion rate of $45.7 \%$ (16 cases). Mean surgical time was 143 minutes (range, 55-360 minutes). The mean hospital stay was 2 days, ranging from 1 to 5 days. No complications were encountered as a consequence of the surgical procedure. All patients showed neurophysiological improvement after surgical intervention. A total of 34 patients (97.14\%) showed clinical improvement at the end of follow-up, averaging 17 months and ranging from 1 to 60 months, 28 patients $(80 \%)$ had good to excellent Macnab outcomes, 6 patients $(17.14 \%)$ were rated as fair, and $1(2.86 \%)$ patient had a poor Macnab outcome. Radicular VAS scores significantly changed $(P<.05)$ from a preoperative 
Table 2. Summary of clinical series.

\begin{tabular}{|c|c|c|c|c|c|c|c|c|c|c|c|c|}
\hline Case & $\begin{array}{c}\text { Age, } \\
\text { y }\end{array}$ & Gender & Segment & Side & $\begin{array}{c}\text { A.S. } \\
\text { Pathologies }\end{array}$ & Clinical F. & Surgical Procedure & Fusion & Levels & Complications & Macnab & $\begin{array}{c}\mathrm{F} / \mathrm{u}, \\
\text { months }\end{array}$ \\
\hline 1 & 55 & Female & L5-S1 & Left & $\mathrm{LT}+\mathrm{LS}$ & $\mathrm{A}+\mathrm{R}+\mathrm{P}$ & Simple resection & No & 1 & None & Good & 2 \\
\hline 2 & 73 & Female & Occ-C1 & Left & & $\mathrm{P}$ & Simple resection & No & 1 & None & Good & 36 \\
\hline 3 & 70 & Female & L4-L5 & Right & LS & $\mathrm{A}+\mathrm{R}+\mathrm{H}+\mathrm{P}$ & Resection + FP & No & 1 & None & Fair & 18 \\
\hline 4 & 49 & Female & L4-L5 & Left & $\mathrm{LT}+\mathrm{LS}$ & $\mathrm{A}+\mathrm{R}+\mathrm{P}$ & Resection + MI-TLIF & Early & 1 & None & Excellent & 60 \\
\hline 5 & 53 & Male & L4-L5 & Right & $\mathrm{LT}+\mathrm{LS}$ & $\mathrm{A}+\mathrm{R}$ & Resection + MI-TLIF & Early & 1 & None & Fair & 60 \\
\hline 6 & 80 & Female & L4-L5 & Right & LS & $\mathrm{A}+\mathrm{P}$ & Simple resection & No & 1 & None & Good & 3 \\
\hline 7 & 73 & Female & L4-L5 & Left & $\mathrm{LT}+\mathrm{SFD}$ & $A+R$ & Resection + MI-TLIF & Early & 2 & None & Good & 13 \\
\hline 8 & 49 & Female & L4-L5 & Right & $\mathrm{LT}+\mathrm{SFD}$ & $\mathrm{R}+\mathrm{P}$ & Simple resection & No & 1 & None & Fair & 10 \\
\hline 9 & 54 & Female & L4-L5 & Right & & $\mathrm{R}+\mathrm{P}$ & Resection + FP & Late $(2 \mathrm{y})$ & 1 & None & Excellent & 36 \\
\hline 10 & 60 & Male & $\mathrm{C} 3-\mathrm{C} 4$ & Left & & $\mathrm{A}+\mathrm{R}+\mathrm{P}$ & Resection + FT & No & 3 & None & Fair & 2 \\
\hline 11 & 61 & Male & L4-L5 & Right & & $\mathrm{R}$ & Simple resection & No & 1 & None & Good & 4 \\
\hline 12 & 71 & Female & L4-L5 & Right & $\mathrm{LT}+\mathrm{LS}$ & $\mathrm{A}+\mathrm{R}+\mathrm{P}$ & Simple resection & Late $(6 \mathrm{mo})$ & 1 & None & Poor & 60 \\
\hline 13 & 50 & Female & L4-L5 & Right & $\mathrm{LT}+\mathrm{SFD}$ & $\mathrm{A}+\mathrm{R}+\mathrm{H}+\mathrm{P}$ & Simple resection & No & 1 & None & Good & 12 \\
\hline 14 & 57 & Female & L4-L5 & Bilateral & LT & $\mathrm{A}+\mathrm{R}+\mathrm{P}$ & Resection + MI-TLIF & Early & 1 & None & Excellent & 24 \\
\hline 15 & 67 & Female & L4-L5 & Right & LS & $A+R+P$ & Simple resection & No & 2 & None & Excellent & 24 \\
\hline 16 & 62 & Female & L4-L5 & Right & LT & $\mathrm{A}+\mathrm{R}+\mathrm{H}+\mathrm{P}$ & Resection + MI-TLIF & Yes & 2 & None & Fair & 6 \\
\hline 17 & 67 & Female & L4-L5 & Right & SFD & $\mathrm{R}$ & Simple resection & No & 1 & None & Excellent & 48 \\
\hline 18 & 52 & Male & L4-L5 & Right & LT & $\mathrm{A}+\mathrm{R}+\mathrm{H}$ & Resection + MI-TLIF & Early & 2 & None & Excellent & 1 \\
\hline 19 & 47 & Male & L5-S1 & Right & SFD & $\mathrm{A}+\mathrm{R}+\mathrm{H}+\mathrm{P}$ & Simple resection & Late $(2 \mathrm{y})$ & 1 & None & Excellent & 24 \\
\hline 20 & 76 & Female & L4-L5 & Right & $\mathrm{LT}+\mathrm{SFD}$ & $\mathrm{A}+\mathrm{R}+\mathrm{P}$ & Resection + FP & No & 1 & None & Good & 24 \\
\hline 21 & 71 & Female & L5-S1 & Left & & $\mathrm{A}+\mathrm{R}+\mathrm{H}+\mathrm{P}$ & Simple resection & No & 1 & None & Good & 1 \\
\hline 22 & 72 & Male & L4-L5 & Left & & $\mathrm{A}+\mathrm{R}+\mathrm{H}+\mathrm{P}$ & Simple resection & No & 1 & None & Excellent & 36 \\
\hline 23 & 78 & Female & L4-L5 & Left & $\mathrm{LT}+\mathrm{LS}$ & $A+R$ & Resection + MI-TLIF & Early & 1 & None & Good & 24 \\
\hline 24 & 63 & Male & L5-S1 & Left & $\ldots$ & $A+R$ & Resection + MI-TLIF & Early & 2 & None & Excellent & 2 \\
\hline 25 & 72 & Female & L4-L5 & Left & & $\mathrm{R}$ & Simple resection & No & 1 & None & Excellent & 2 \\
\hline 26 & 55 & Female & L4-L5 & Right & $\mathrm{LT}+\mathrm{LS}$ & $A+R+P$ & Resection + MI-TLIF & Early & 3 & None & Good & 6 \\
\hline 27 & 58 & Female & L4-L5 & Left & $\mathrm{LT}+\mathrm{LS}$ & $\mathrm{A}+\mathrm{R}+\mathrm{H}+\mathrm{P}$ & Resection + MI-TLIF & Early & 2 & None & Good & 18 \\
\hline 28 & 63 & Male & L5-S1 & Left & SFD & $A+R$ & Simple resection & No & 1 & None & Excellent & 3 \\
\hline 29 & 53 & Male & L5-S1 & Left & & $\mathrm{R}+\mathrm{H}+\mathrm{P}$ & Resection + FP & No & 1 & None & Good & 3 \\
\hline 30 & 75 & Female & $\begin{array}{l}\text { L3-L4 and } \\
\text { L4-L5 }\end{array}$ & Right & SFD & $\mathrm{A}+\mathrm{R}$ & Resection + FP & No & 2 & None & Fair & 6 \\
\hline 31 & 49 & Female & L5-S1 & Left & SFD & $A+R$ & Resection + MI-TLIF & Early & 1 & None & Good & 6 \\
\hline 32 & 66 & Female & L4-L5 & Right & LT & $A+R$ & Resection + MI-TLIF & Early & 2 & None & Good & 4 \\
\hline 33 & 63 & Female & L3-L4 & Left & SFD & $A+R$ & Resection + FP & No & 2 & None & Good & 6 \\
\hline 34 & 66 & Female & L5-S1 & Left & LT & $\mathrm{R}+\mathrm{H}+\mathrm{P}$ & Resection + FP & No & 2 & None & Excellent & 4 \\
\hline 35 & 78 & Female & L5-L6 & Left & LT & $\mathrm{A}+\mathrm{R}+\mathrm{P}$ & Resection + MI-TLIF & Early & 1 & None & Good & 1 \\
\hline
\end{tabular}

Abbreviations: A, axial pain; A.S. Pathologies, associated spine pathologies; Clinical F., clinical findings; CL-SS-SC, contralateral same segment synovial cyst; FP, foraminoplasty, foraminotomy; H, hyposthesia; LS, lumbar stenosis; LT, listhesis; MI-TLIF, minimally invasive transforaminal lumbar interbody fusion; P, paresis; R, radicular pain; SFD, severe facet degeneration; Occ, Occiput.

Table 3. Postoperative clinical outcomes.

\begin{tabular}{lc}
\hline Fusion & $N(\%)$ \\
Early & $13(37.14)$ \\
Late & $3(8.57)$ \\
Total & $16(45.71)$ \\
Cyst recurrence & $1(2.5)$ \\
De novo & $1(2.85)$ \\
Postoperative Macnab & $N(\%)$ \\
Excellent/good & $12(34.29)$ \\
Good & $16(45.71)$ \\
Fair & $6(17.14)$ \\
Poor & $1(2.85)$ \\
Primary postoperative outcome scores & Mean \\
VAS Preoperative & 8 \\
VAS Postoperative & 2.25 \\
ODI Preoperative & 35.7 \\
ODI Postoperative & 14.29 \\
Mean surgical time & $143 \mathrm{~min}$ \\
Complications & None \\
Mean hospital stay & $2 \mathrm{~d}$ \\
Mean follow-up & $16.8 \mathrm{mo}$ \\
\hline
\end{tabular}

Abbreviations: ODI, Oswestry disability index; VAS, visual analog scale. mean of 8.23 (range, 6-10) to a postoperative mean of 2.23 (range, $0-9)$. ODI significantly decreased $(P$ $<.05$ ) from a preoperative mean of 41.02 (range, 14-60) to a postoperative mean of 11.82 (range, 0 54). Table 3 summarizes the relevant postoperative clinical data. These VAS leg score and ODI reductions were statistically significant (Tables 4 and 5). The case with poor outcomes developed a recurrence in the same surgical site, and another patient developed a de novo synovial cyst in the contralateral segment.

Table 4. Paired sample $t$ test of preoperative and postoperative VAS leg and ODI scores.

\begin{tabular}{lrrrc}
\hline Test & Mean & $\boldsymbol{N}$ & $\begin{array}{r}\text { Standard } \\
\text { Deviation }\end{array}$ & $\begin{array}{c}\text { Standard Error } \\
\text { of the Mean }\end{array}$ \\
\hline VAS leg, preoperative & 8.2286 & 35 & 1.23873 & 0.20938 \\
VAS leg, postoperative & 2.2286 & 35 & 1.94158 & 0.32819 \\
ODI, preoperative & 41.0294 & 34 & 12.55892 & 2.15384 \\
ODI, postoperative & 11.8235 & 34 & 10.56429 & 1.81176 \\
\hline
\end{tabular}

Abbreviations: ODI, Oswestry disability index; VAS, visual analog scale. 
Table 5. Paired differences of preoperative and postoperative VAS leg and ODI scores.

\begin{tabular}{|c|c|c|c|c|c|c|c|c|}
\hline \multirow[b]{2}{*}{ Comparison } & \multicolumn{2}{|c|}{ Paired Differences } & \multirow{2}{*}{$\begin{array}{l}\text { Standard } \\
\text { Error of the } \\
\text { Mean }\end{array}$} & \multicolumn{2}{|c|}{$\begin{array}{l}95 \% \text { Confidence Interval } \\
\text { of the Difference }\end{array}$} & \multirow[b]{2}{*}{$t$} & \multirow[b]{2}{*}{ df } & \multirow{2}{*}{$\begin{array}{c}P \text { Value } \\
\text { (Two-Tailed) }\end{array}$} \\
\hline & Mean & Standard Deviation & & Lower & Upper & & & \\
\hline VAS leg, preoperative-postoperative & 6.00000 & 2.33893 & 0.39535 & 5.19655 & 6.80345 & 15.176 & 34 & .000 \\
\hline ODI, preoperative-postoperative & 29.20588 & 15.73219 & 2.69805 & 23.71666 & 34.69510 & 10.825 & 33 & .000 \\
\hline
\end{tabular}

Abbreviations: ODI, Oswestry disability index; VAS, visual analog scale.

\section{DISCUSSION}

Our clinical series compares favorably to reported series in the current literature. Radiculopathy was the main symptom followed by axial pain. Nevertheless, muscle weakness showed a higher incidence rate $(68.6 \%$ compared with $32-40 \%$ reported rate). ${ }^{3,10,21}$ In the present series, we observed similar mean age and a slightly higher rate of female predominance $(74.3 \%)$ than more extensive series $(50-67 \%))^{13,25,38}$

Birch et $\mathrm{al}^{13}$ reported a history of prior surgery in $2.5 \%$ of cases compared with our incidence rate of $14.3 \%$. Due to a high percentage of comorbidities, including spondylolisthesis, severe facet degeneration, and lumbar stenosis, many of our patients required an extended surgical procedure and early fusion with MI-TLIF and supplemental posterior transpedicular fixation. The authors agree with prior reports in that the natural history of synovial facet cysts is likely related to the progression of instability of the involved lumbar spinal motion segment, as was seen in the 8 patients $(22.9 \%)$ requiring primary fusion and in the 3 patients $(8.57 \%)$ ultimately requiring late fusion, contributing to a final fusion rate of $45.7 \%$ (16 cases). ${ }^{38}$ Our findings of higher rates of subsequent adjacent segment pathology $(22.9 \%)$ and symptomatic disease $(8.57 \%)$ are corroborated by many prior reports. . $^{1,8,10,11,13,25}$

Our series includes one case of a de novo synovial cyst generation at the contralateral side of initial resection, advocating a clear role in instability development to synovial cyst pathology. The most frequent site of the synovial cyst was L4-L5, as in most series. Our initial fusion rate was $37.14 \%$ (13 patients); however, $48.6 \%$ of patients had preexisting spondylolisthesis in an otherwise asymptomatic and initially unrelated segment. Therefore, 3 more patients ultimately required secondary fusion, increasing the final fusion rate to $45.71 \%$.

The main limitation of the current study is its single-surgeon and single-center nature. Therefore, favorable outcomes could have been artificially inflated by using our reproducible surgical protocol since all of our team members had already mastered the learning curve. Our favorable clinical results may not be reproducible to this extent by surgeons with less clinical support or training. Another limitation is the retrospective nature of our study. We attempted to minimize selection, recall, or hindsight bias by incorporating diagnostic facet and nerve blocks. ${ }^{39-41}$ Lastly, a short follow-up (mean of 16.8 months) could be considered as problematic even though long-term follow-up was available in several early patients (follow-up to 60 months).

\section{CONCLUSIONS}

Clinical outcomes of our series with the surgical treatment of synovial cysts in the spine are comparable to prior reports. Synovial cysts are uncommon in the cervical and thoracic spine. The present work shows the efficacy and safety of minimally invasive surgery using a tubular retractor system in the treatment of these lesions, many of them requiring fusion due to instability related to the underlying degenerative disease of the spinal motion segment and its progression. ${ }^{26} \mathrm{~A}$ high rate of spondylolisthesis, adjacent segment disease, or development of a synovial cyst on the contralateral side of the primary cyst resection should be expected.

\section{REFERENCES}

1. Boviatsis EJ, Stavrinou LC, Kouyialis AT, et al. Spinal synovial cysts: pathogenesis, diagnosis and surgical treatment in a series of seven cases and literature review. Eur Spine $J$ 2008;17(6):831-837. doi:10.1007/s00586-007-0563-z

2. Khan AM Girardi F. Spinal lumbar synovial cysts. Diagnosis and management challenge. Eur Spine $J$ 2006;15(8):1176-1182. doi:10.1007/s00586-005-0009-4

3. Lyons MK, Atkinson JL, Wharen RE, et al. Surgical evaluation and management of lumbar synovial cysts: the Mayo Clinic experience. J Neurosurg 2000;93(1 Suppl):53-57. doi:10. 3171/spi.2000.93.1.0053

4. Bruder M, Gessler F, Cattani A, et al. Surgical Treatment of Spinal Synovial Cysts in Elderly Patients: Symptoms, 
Treatment Course, and Outcome in Patients $>75$ Years of Age. World Neurosurg 2018;110:e520-e525. doi:10.1016/j.wneu.2017. 11.031

5. Bydon M, Papadimitriou K, Witham T, et al. Treatment of spinal synovial cysts. World Neurosurg 2013;79(2):375-380. doi:10.1016/j.wneu.2012.08.016

6. Ganau M, Ennas F, Bellisano G, et al. Synovial cysts of the lumbar spine-pathological considerations and surgical strategy. Neurol Med Chir (Tokyo) 2013;53(2):95-102. doi:10. 2176/nmc.53.95

7. Schroder J, Fischer B, Stefan P, et al. Spinal synovial cysts: clinical and therapeutic considerations. Zentralbl Neurochir 2008;69(3):125-128 doi:10.1055/s-2008-1077078

8. Abd El-Kader Hel-B. Juxtafacet Spinal Synovial Cysts. Asian Spine J 2016;10:46-51.doi:10.4184/asj.2016.10.1.46

9. Jankowski R, Szymas J, Nowak S, et al. Synovial cysts of the lumbar spine. Neurol Neurochir Pol 2012;46(5):456-461 doi:10.5114/ninp.2012.31356

10. Bydon A, Xu R, Parker SL, et al. Recurrent back and leg pain and cyst reformation after surgical resection of spinal synovial cysts: systematic review of reported postoperative outcomes. Spine J 2010;10(9):820-826 doi:10.1016/j.spinee. 2010.04.010

11. Campbell RJ, Mobbs RJ, Rao PJ, et al. Interventions for Lumbar Synovial Facet Joint Cysts: A Comparison of Percutaneous, Surgical Decompression and Fusion Approaches. World Neurosurg 2017;98:492-502. doi:10.1016/j.wneu.2016. 11.044

12. Scholz C, Hubbe U, Kogias E, et al. Incomplete resection of lumbar synovial cysts-Evaluating the risk of recurrence. Clin Neurol Neurosurg 2015;136:29-32. doi:10.1016/j.clineuro. 2015.05.028

13. Birch BD, Aoun RJN, Elbert GA, et al. Minimally Invasive Tubular Resection of Lumbar Synovial Cysts: Report of 40 Consecutive Cases. World Neurosurg 2016;94:188-196. doi:10.1016/j.wneu.2016.06.125

14. Sehati N, Khoo LT, Holly LT. Treatment of lumbar synovial cysts using minimally invasive surgical techniques. Neurosurg Focus 2006;20(3):E2 doi:10.3171/foc.2006.20.3.3

15. Sukkarieh HG, Hitchon PW, Awe O, et al. Minimally invasive resection of lumbar intraspinal synovial cysts via a contralateral approach: review of 13 cases. J Neurosurg Spine 2015;23(4):444-450. doi:10.3171/2015.1.SPINE14996

16. Vergara P, Akhunbay-Fudge CY, Kotter MR, et al. Minimally Invasive Versus Open Surgery for Lumbar Synovial Cysts. World Neurosurg 2017;108:555-559. doi:10.1016/j.wneu. 2017.09.039

17. James A, Laufer I, Parikh K, et al. Lumbar juxtafacet cyst resection: the facet sparing contralateral minimally invasive surgical approach. J Spinal Disord Tech 2012;25(2):E13-17. doi:10.1097/BSD.0b013e31822ac4e5

18. Rhee J, Anaizi AN, Sandhu FA, et al. Minimally invasive resection of lumbar synovial cysts from a contralateral approach. J Neurosurg Spine 2012;17(5):453-458. doi:10.3171/ 2012.8.SPINE12101

19. Bydon M, Lin JA, de la Garza-Ramos R, et al. The role of spinal fusion in the treatment of cervical synovial cysts: a series of 17 cases and meta-analysis. J Neurosurg Spine 2014;21(6):919-928. doi:10.3171/2014.8.SPINE13897

20. Knafo S, Page P, Pallud J, et al. Surgical Management of Spinal Synovial Cysts: A Series of 23 Patients and Systematic
Analysis of the Literature. J Spinal Disord Tech 2015;28(6):211217. doi:10.1097/BSD.0b013e31827179c8

21. Bruder M, Cattani A, Gessler F, et al. Synovial cysts of the spine: long-term follow-up after surgical treatment of 141 cases in a single-center series and comprehensive literature review of 2900 degenerative spinal cysts. J Neurosurg Spine 2017;27(3):256-267. doi:10.3171/2016.12.SPINE16756

22. Gadgil AA, Eisenstein SM, Darby A, et al. Bilateral symptomatic synovial cysts of the lumbar spine caused by calcium pyrophosphate deposition disease: a case report. Spine (Phila Pa 1976) 2002;27(19):E428-E431. doi:10.1097/ 00007632-200210010-00024

23. Pirotte B, Gabrovsky N, Massager N, et al. Synovial cysts of the lumbar spine: surgery-related results and outcome. J Neurosurg 2003;99(1 Suppl):14-19. doi:10.3171/spi.2003.99.1. 0014

24. Rousseaux P, Durot JF, Pluot M, et al. Kystes synoviaux et synovialomes du rachis lombaire. Aspects histo-pathologiques et neuro-chirurgicaux à propos de 8 observations [Synovial cysts and synovialomas of the lumbar spine. Histo-pathologic and neuro-surgical aspects apropos of 8 cases]. Neurochirurgie 1989;35(1):31-39.

25. Xu R, McGirt MJ, Parker SL, et al. Factors associated with recurrent back pain and cyst recurrence after surgical resection of one hundred ninety-five spinal synovial cysts: analysis of one hundred sixty-seven consecutive cases. Spine (Phila Pa 1976) 2010;35(10):1044-1053. doi:10.1097/BRS. 0b013e3181bdafed

26. Epstein NE. Lumbar laminectomy for the resection of synovial cysts and coexisting lumbar spinal stenosis or degenerative spondylolisthesis: an outcome study. Spine (Phila Pa 1976) 2004;29(9):1049-1055; discussion 1056. doi:10.1097/ 00007632-200405010-00018

27. Ruetten S, Hahn P, Oezdemir S, et al. Surgical treatment of cervical subaxial intraspinal extradural cysts using a fullendoscopic uniportal posterior approach. J Orthop Surg (Hong Kong) 2018;26(2):2309499018777665. doi:10.1177/ 2309499018777665

28. Themistoklis KM, Papasilekas TI, Boviatsis KA, et al. Spinal synovial cysts. A case series and current treatment options. J Clin Neurosci 2018;57:173-177. doi:10.1016/j.jocn. 2018.08.038

29. Lin WL, Lee MS, Wong CS, et al. Effects of intraoperative propofol-based total intravenous anesthesia on postoperative pain in spine surgery: Comparison with desflurane anesthesia - a randomised trial. Medicine (Baltimore) 2019;98(13):e15074. doi:10.1097/MD.0000000000015074

30. Uribe AA, Mendel E, Peters ZA, et al. Comparison of visual evoked potential monitoring during spine surgeries under total intravenous anesthesia versus balanced general anesthesia. Clin Neurophysiol 2017;128(10):2006-2013. doi:10.1016/j. clinph.2017.07.420

31. Thomas B. Remifentanil versus fentanyl in total intravenous anesthesia for lumbar spine surgery: a retrospective cohort study. J Clin Anesth 2015;27(5):391-395. doi:10.1016/j. jclinane.2015.03.024

32. Sloan TB, Toleikis JR, Toleikis SC, et al. Intraoperative neurophysiological monitoring during spine surgery with total intravenous anesthesia or balanced anesthesia with $3 \%$ desflurane. J Clin Monit Comput 2015;29(1):77-85. doi:10. 1007/s10877-014-9571-9

33. Ilvan G, Özköse HZ. The effect of total intravenous 
anesthesia on the postoperative cognitive functions of young and elderly patients after lumbar disk surgery. Turk $J$ Med Sci 2015;45(1):191-196. doi:10.3906/sag-1311-29

34. Huskisson EC, Jones J, Scott PJ. Application of visualanalogue scales to the measurement of functional capacity. Rheumatol Rehabil 1976;15(3):185-187. doi:10.1093/ rheumatology/15.3.185

35. Fairbank JC, Pynsent PB. The Oswestry Disability Index. Spine (Phila Pa 1976) 2000;25(22):2940-2952; discussion 2952. doi:10.1097/00007632-200011150-00017

36. Fairbank J. Use of Oswestry Disability Index (ODI). Spine (Phila Pa 1976) 1995;20(13):1535-1537.

37. Liberati A, Altman DG, Tetzlaff J, et al. The PRISMA statement for reporting systematic reviews and meta-analyses of studies that evaluate healthcare interventions: explanation and elaboration. BMJ 2009;339:b2700. doi:10.1136/bmj.b2700

38. Lee MJ, Dettori JR, Standaert CJ, et al. The natural history of degeneration of the lumbar and cervical spines: a systematic review. Spine (Phila Pa 1976) 2012;37(22 Suppl):S18-30. doi:10.1097/BRS.0b013e31826cac62

39. Sibbald M, Sherbino J, Ilgen JS, et al. Correction to: Debiasing versus knowledge retrieval checklists to reduce diagnostic error in ECG interpretation. Adv Health Sci Educ Theory Pract 2019;24(3):441-442. doi:10.1007/s10459-01909884-7

40. Solberg T, Johnsen LG, Nygaard OP, et al. Can we define success criteria for lumbar disc surgery? : estimates for a substantial amount of improvement in core outcome measures. Acta Orthop 2013;84(2):196-201. doi:10.3109/17453674.2013. 786634

41. Zwaan L, Monteiro S, Sherbino J, et al. Is bias in the eye of the beholder? A vignette study to assess recognition of cognitive biases in clinical case workups. BMJ Qual Saf. 2017;26(2):104-110. doi:10.1136/bmjqs-2015-005014

Disclosures and COI: We have no conflicts of interest nor any financial relationship or funding to disclose.

Corresponding Author: Kai Uwe Lewandrowski, MD, Center for Advanced Spine Care of Southern Arizona, Tucson, AZ 85712. Phone: (520) 204-1495; Fax: (623) 218-1215; Email: business@ tucsonspine.com.

Published 0 Month 2021

This manuscript is generously published free of charge by ISASS, the International Society for the Advancement of Spine Surgery. Copyright $\odot 2021$ ISASS. To see more or order reprints or permissions, see http://ijssurgery.com. 